\title{
Ultrasound-guided central venous catheter placement increases success rates in pediatric patients: a meta-analysis
}

\author{
Christine S.M. Lau ${ }^{1,2}$ and Ronald S. Chamberlain ${ }^{1,2,3}$
}

BACKGROUND: Real-time ultrasound (US) guidance for central venous catheter (CVC) insertion has been shown to increase cannulation success rates and reduce complications in adults. Literature regarding US-guided CVC placement in children remains limited and conflicting. This meta-analysis examines the efficacy and safety of US-guided CVC placement among pediatric patients.

METHODS: A comprehensive literature search of all published randomized control trials (RCTs) comparing the use of real-time US-guided CVC insertion with anatomic landmark (LM)-guided CVC insertion in pediatric patients $<18$ y of age was conducted. Outcomes analyzed were cannulation success rate, number of attempts required, incidence of accidental arterial puncture, and time to cannulation.

RESULTS: Eight RCTs involving 760 patients were analyzed. US-guided CVC insertion significantly increased success rates by $31.8 \%$ and decreased the mean number of attempts required. A trend toward a decrease in the risk of accidental arterial puncture with the use of US-guided CVC insertion was also observed. US-guided CVC insertion was not associated with a significant difference in time required for CVC placement.

CONCLUSION: US-guided CVC placement is associated with significantly higher success rates and decreased mean number of attempts required for cannulation. US-guided CVC insertion improves success rates, and should be utilized in pediatric patients.

c entral venous catheter (CVC) placement is a commonly performed procedure for hemodynamic monitoring, fluid and antibiotic administration, total parenteral nutrition, and hemodialysis (1). Common sites for CVC access include the internal jugular, subclavian, and femoral veins (2). CVC access has traditionally been achieved by visualizing or palpating anatomical landmarks (3). Although landmark (LM)-guided techniques have been associated with high levels of success, aberrant anatomy and previous catheterizations often complicate this procedure resulting in decreased success $(3,4)$. CVC placements are associated with significant risks and complications, including cervical hematoma, cardiac tamponade, and even death in rare cases $(3,4)$.
Ultrasound (US)-guided CVC insertion, first described in 1986 by Yonei $e t$ al., has been studied extensively and utilized in various settings (5). The current National Institute for Clinical Excellence (2002) recommendations state that US guidance is the preferred method for elective CVC insertion in both adults and children (6). The most common US modality utilized in CVC insertion is two-dimensional (2D) US guidance (3). Wu et al. (7) conducted a meta-analysis involving 26 randomized control trials (RCT) and 4,185 patients (2,081 with US guidance and 2,104 with LM guidance) and reported an $82 \%$ reduction in cannulation failure (relative risk $(\mathrm{RR})=0.18 ; 95 \%$ confidence interval (CI): $0.10-0.32 ; P<0.001$ ) with 2D US-guided CVC insertion, as well as a significant reduction in complications including arterial puncture, hematoma, pneumothorax, and hemothorax $(P<0.05)$. Lee and Chamberlain $(8)$ conducted a meta-analysis involving 17 RCTs and 3,686 adult patients (1,822 with US guidance and 1,684 with LM guidance) and reported a $14 \%$ increase in cannulation success rate among junior operators $(\mathrm{RR}=1.14$; 95\% CI: 1.08-1.2; $P<0.001)$ and a 7\% increase among senior operators (RR $=1.08$; 95\% CI: $1.02-1.14 ; P=0.011)$. Numerous other studies have reported similar improvements in success rates and reductions in complication rates with the use of US $(1,7,9)$.

While there is clear consensus on the benefits of US-guided CVC insertion in adults, existing evidence for similar benefit in US-guided CVC insertion in the pediatric population remains limited, controversial, or nonexistent (3,5,7). Aouad et al. (10) conducted a RCT involving 48 children (24 with US guidance and 24 with LM guidance), and reported higher cannulation success rates on first attempts ( 75.0 vs. $25.0 \%, P=0.001)$ with the use of US among junior resident physicians. Conversely, Grebenik et al. (6) conducted a RCT involving 124 children (59 with US guidance and 65 with LM guidance), and reported a significantly lower success rate ( 80.0 vs. $89.2 \%, P<0.02)$ with the use of US-guided CVC insertion among experienced anesthesiologists.

This current meta-analysis provides a comprehensive review of the use of real-time US-guided CVC insertion in pediatric patients $<18 \mathrm{y}$ of age. Given the difficulties in achieving cannulation in children and the high rate of accidental arterial punctures, the use of real-time US may have a role in the future care of children requiring CVC access. Literature on the use of US-guided CVC insertion in adults 
demonstrate clear benefits including improved success and reduced complications, and similar benefits are expected among pediatric patients.

\section{RESULTS}

\section{Demographic Characteristics of the Studies}

A total of eight RCTs were identified, involving 760 children (Table 1 and Supplementary Table S1 online). Three hundred and sixty-seven children underwent real-time US-guided CVC insertion and 393 children underwent anatomic LM-guided CVC insertion.

\section{Effects of Real-Time US-Guided CVC Insertion on Success Rate}

Data on the overall success rate of CVC placement for both the US-guided and LM-guided groups were reported in all trials. There was significant heterogeneity between trials $(P<0.001$, $\left.I^{2}=83.434\right)$, and a random-effects model was assumed. Metaanalysis showed a significant increase in the overall likelihood of successful CVC placement with the use of US guidance (RR $=1.32 ; 95 \%$ CI: 1.10-1.58; $P=0.003$ ) (Figure 1).

\section{Effects of Real-Time US-Guided CVC Insertion on Number of Attempts Required}

Data on the number of attempts required for CVC placement in both the US-guided and LM-guided groups were reported in five studies, involving 454 children (226 with US guidance and 228 with LM guidance). There was significant heterogeneity between trials $\left(P=0.017, I^{2}=66.725\right)$, and a random-effects model was assumed. Meta-analysis showed a significant reduction in the number of required attempts with the use of US guidance (difference in means $(\mathrm{MD})=-1.26$ attempts; $95 \% \mathrm{CI}:-1.71$ to $-0.81 ; P<0.001$ ) (Figure 2 ).

\section{Effects of Real-Time US-Guided CVC Insertion on Accidental Arterial Puncture}

Data on the incidence of accidental arterial puncture in both the US-guided and LM-guided groups were reported in all trials. There was significant heterogeneity between trials $(P=$ $0.006, I^{2}=64.523$ ), and a random-effects model was assumed. Meta-analysis showed a reduction in the risk of accidental arterial puncture with the use of US guidance, although the results did not reach statistical significance $(\mathrm{RR}=0.36$; $95 \% \mathrm{CI}$ : 0.12-1.09; $P=0.071$ ) (Figure 3).

\section{Effects of Real-Time US-Guided CVC Insertion on Time to Cannulation}

Data on the mean time to cannulation in both the US-guided and LM-guided groups were reported in four trials, involving 291 children (138 with US guidance and 153 with LM guidance). There was significant heterogeneity between

Table 1. Characteristics of included randomized control trials evaluating the use of real-time ultrasound-guided central venous catheter insertion in pediatric populations (1966-2015)

\begin{tabular}{|c|c|c|c|c|c|c|}
\hline $\begin{array}{l}\text { Study, year } \\
\text { (reference) }\end{array}$ & $\begin{array}{l}\text { Number of } \\
\text { patients (\# } \\
\text { ultrasound, \# } \\
\text { landmark) }\end{array}$ & $\begin{array}{l}\text { Location of } \\
\text { central venous } \\
\text { catheter }\end{array}$ & Inclusion criteria & Age of children & Operator & $\begin{array}{l}\text { Jadad } \\
\text { score }\end{array}$ \\
\hline $\begin{array}{l}\text { Alderson, } 1993 \\
(22)\end{array}$ & $40(20,20)$ & $\begin{array}{l}\text { Internal jugular } \\
\text { vein }\end{array}$ & $\begin{array}{l}\text { Children }<6 \text { y of age } \\
\text { undergoing cardiac } \\
\text { surgery }\end{array}$ & Children $<6$ y & $\begin{array}{l}\text { Experienced cardiac } \\
\text { anesthetist }\end{array}$ & 2 \\
\hline $\begin{array}{l}\text { Verghese, } 1999 \\
\text { (23) }\end{array}$ & $95(43,52)$ & $\begin{array}{l}\text { Internal jugular } \\
\text { vein }\end{array}$ & $\begin{array}{l}\text { Infants }<12 \text { mo and } \\
<10 \mathrm{~kg} \text { scheduled for } \\
\text { cardiovascular surgery }\end{array}$ & Infants $<12 \mathrm{mo}$ & $\begin{array}{l}\text { Board eligible pediatric } \\
\text { anesthesia fellow, supervised } \\
\text { by cardiac anesthesiologist }\end{array}$ & 3 \\
\hline $\begin{array}{l}\text { Verghese, } 2000 \\
(24)\end{array}$ & $32(16,16)$ & $\begin{array}{l}\text { Internal jugular } \\
\text { vein }\end{array}$ & $\begin{array}{l}\text { Infants }<12 \text { mo and } \\
<10 \mathrm{~kg} \text { scheduled for } \\
\text { cardiovascular surgery }\end{array}$ & Infants $<12$ mo & $\begin{array}{l}\text { Board eligible pediatric } \\
\text { anesthesia fellow, supervised } \\
\text { by cardiac anesthesiologist }\end{array}$ & 3 \\
\hline $\begin{array}{l}\text { Grebenik, } 2004 \\
\text { (6) }\end{array}$ & $124(59,65)$ & $\begin{array}{l}\text { Internal jugular } \\
\text { vein }\end{array}$ & $\begin{array}{l}\text { Pediatric patients } \\
\text { scheduled for cardiac } \\
\text { surgery }\end{array}$ & Children $<8 y$ & $\begin{array}{l}\text { Consultant pediatric cardiac } \\
\text { anesthetist, with minimum of } \\
\text { five prior successful US-guided } \\
\text { CVC placements }\end{array}$ & 3 \\
\hline $\begin{array}{l}\text { Chuan, } 2005 \\
\text { (25) }\end{array}$ & $62(32,30)$ & $\begin{array}{l}\text { Internal jugular } \\
\text { vein }\end{array}$ & $\begin{array}{l}\text { Patients undergoing } \\
\text { elective surgery for } \\
\text { congenital heart disease }\end{array}$ & Infants and children $<12 \mathrm{~kg}$ & Not specified & 3 \\
\hline $\begin{array}{l}\text { Ovezov, } 2010 \\
(26)\end{array}$ & $209(107,102)$ & $\begin{array}{l}\text { Internal jugular } \\
\text { vein }\end{array}$ & $\begin{array}{l}\text { Children under } \\
\text { anesthesia and } \\
\text { intensive care }\end{array}$ & $\begin{array}{l}\text { Infants and children (mean } \\
\text { age: } 53 \text { mo in US-guided } \\
\text { CVC group, } 52 \text { mo in } \\
\text { landmark group) }\end{array}$ & Not specified & 4 \\
\hline $\begin{array}{l}\text { Aouad, } 2010 \\
\text { (10) }\end{array}$ & $48(24,24)$ & Femoral vein & $\begin{array}{l}\text { Pediatric patients with } \\
\text { congenital heart disease } \\
\text { undergoing cardiac } \\
\text { surgery }\end{array}$ & Children $<12$ y & Resident physicians & 3 \\
\hline $\begin{array}{l}\text { Bruzoni, } 2013 \\
\text { (11) }\end{array}$ & $150(66,84)$ & $\begin{array}{l}\text { Subclavian vein, } \\
\text { internal jugular } \\
\text { vein }\end{array}$ & $\begin{array}{l}\text { Pediatric patients }<18 \\
\text { y undergoing CVC } \\
\text { placement under general } \\
\text { anesthesia }\end{array}$ & Children $<18$ y & $\begin{array}{l}\text { Attending pediatric surgeons } \\
\text { or pediatric surgery fellows }\end{array}$ & 3 \\
\hline
\end{tabular}

CVC, central venous catheter; US, ultrasound. 


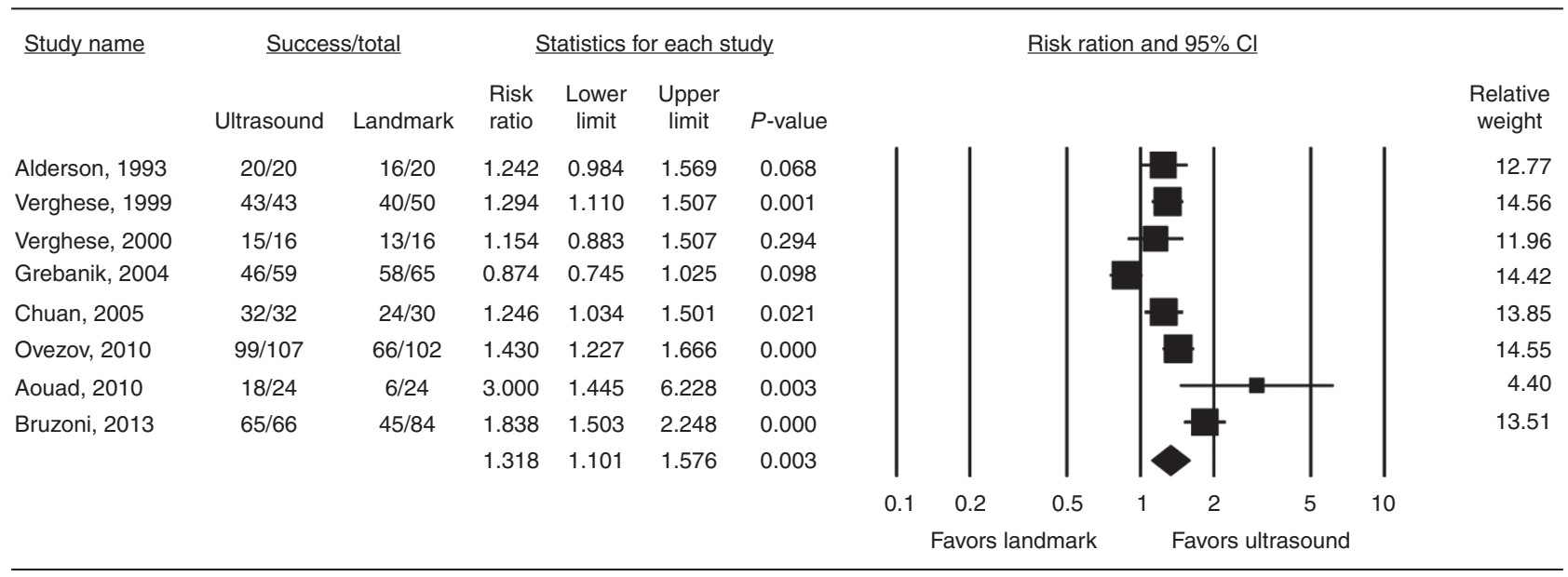

Figure 1. Forest plot evaluating the relative risk of successful central venous catheter placement with the use of ultrasound guidance among pediatric patients (Note: Individual studies are represented by the squares. Overall summaries are represented by the diamonds).

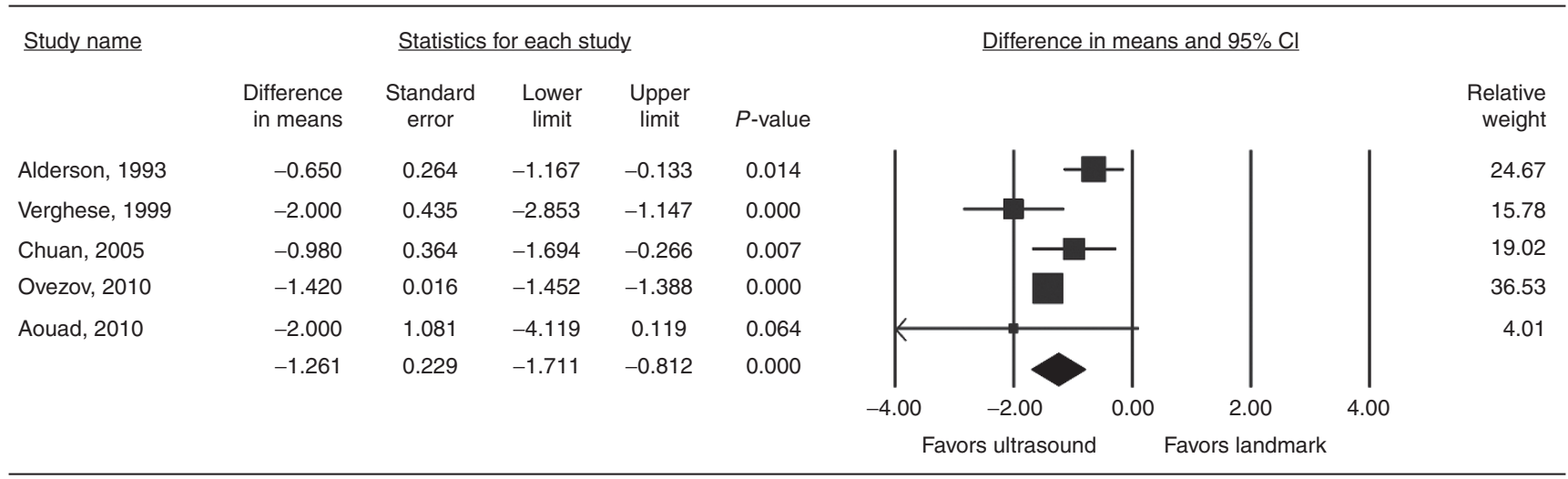

Figure 2. Forest plot evaluating the difference in mean for the number of attempts required for central venous catheter placement with the use of ultrasound guidance among pediatric patients. (Note: Individual studies are represented by the squares. Overall summaries are represented by the diamonds).

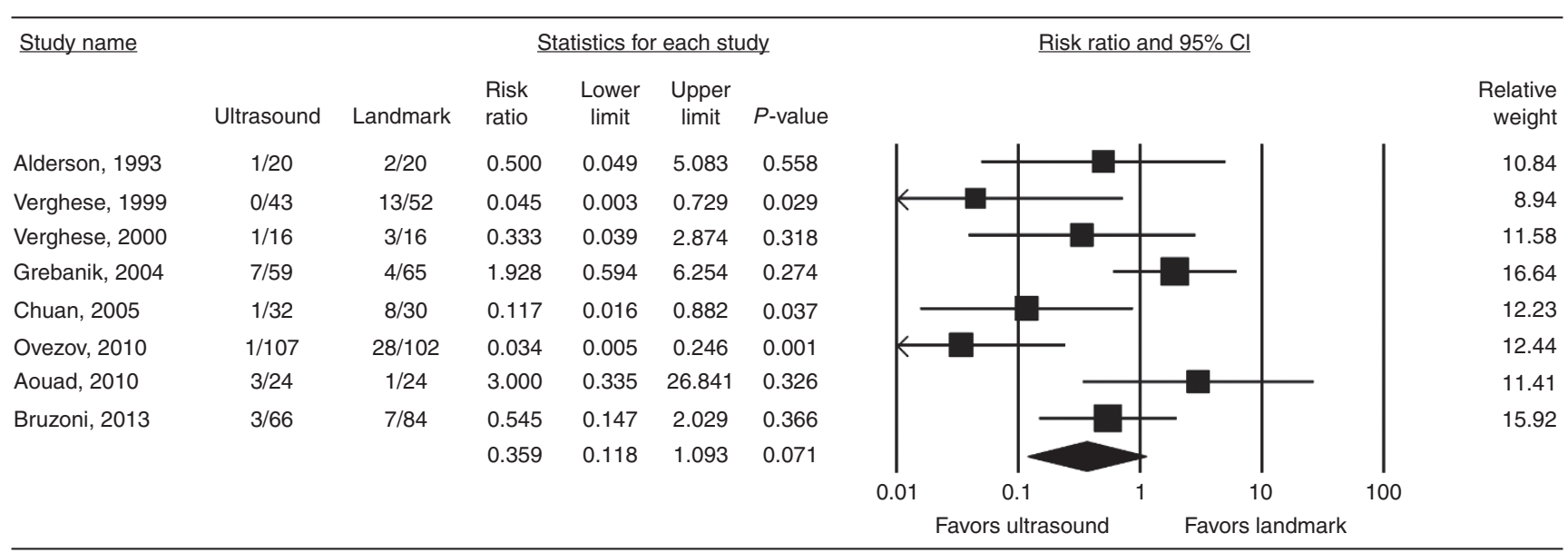

Figure 3. Forest plot evaluating the relative risk of accidental arterial puncture with the use of ultrasound guided central venous catheter insertion among pediatric patients (Note: Individual studies are represented by the squares. Overall summaries are represented by the diamonds).

trials $\left(P<0.001, I^{2}=83.801\right)$, and a random-effect model was assumed. Meta-analysis showed no significant difference in the time required for cannulation with the use of US guidance $(\mathrm{MD}=-1.12 \mathrm{~min} ; 95 \% \mathrm{CI}:-2.60$ to $0.35 ; P=0.136)$ (Figure 4$)$.

\section{Subgroup Analysis by Operator Experience}

Five of the RCTs involved senior operators while one RCT involved junior operators. US guidance improved overall success rates among both junior and senior operators, however, 


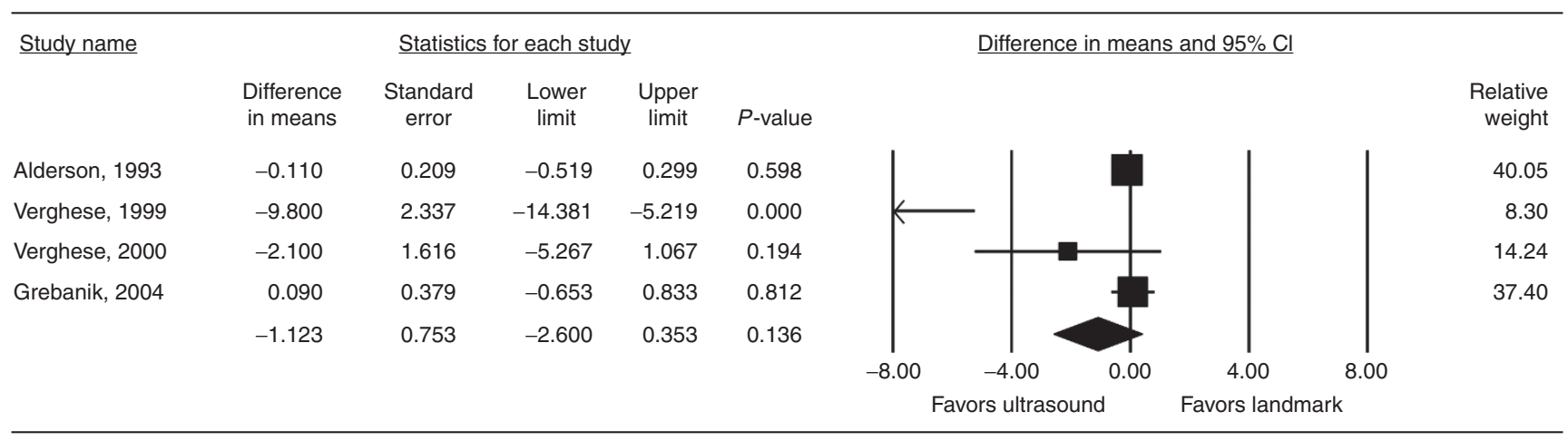

Figure 4. Forest plot evaluating the difference in mean for time to cannulation with the use of ultrasound guided central venous catheter insertion among pediatric patients (Note: Individual studies are represented by the squares. Overall summaries are represented by the diamonds).

junior operators experienced a significantly greater improvement with the use of US guidance, compared to senior operators $(P=0.025)$ (Supplementary Figure S1 online). The risk of accidental arterial puncture was similar between both junior and senior operators $(P=0.111)$ (Supplementary Figure S2 online).

\section{Subgroup Analysis by Site of Cannulation}

Six of the RCTs involved the internal jugular vein, while one RCT involved the femoral vein, and one RCT involved both the subclavian and internal jugular veins. Aouad et al. (10) conducted a RCT involving 48 children (24 with US guidance and 24 with LM guidance), and reported a significantly higher success rate $(75.0$ vs. $25.0 \%, P<0.005)$ with the use of US in femoral vein cannulation, but also had a higher rate of arterial puncture (12.5 vs. $4.2 \%, P=0.6)$. Bruzoni et al. (11) conducted a RCT involving 150 children (66 with US guidance and 84 with LM guidance) receiving either subclavian or internal jugular vein cannulation, and reported a significantly higher success rate ( 98.5 vs. $53.6 \%, P=0.021$ ) with the use of US guidance, with similar rates of complications ( 4.5 vs. $4.7 \%$, $P>0.05)$ and arterial punctures ( 4.5 vs. $8.3 \%, P>0.05)$.

\section{Sensitivity Analyses}

Sensitivity analyses demonstrated similar overall relative risk estimates for cannulation success rate and arterial puncture with the removal of any single study. Cannulation success rates ranged from $24 \%$ increase $(\mathrm{RR}=1.24 ; 95 \% \mathrm{CI}$ : $1.05-1.47 ; P=$ $0.012)$ to $39 \%$ increase $(\mathrm{RR}=1.393 ; 95 \% \mathrm{CI}: 1.22-1.60 ; P<$ 0.001) (Supplementary Figure S3 online). Accidental arterial puncture reductions ranged from a $47 \%$ reduction $(\mathrm{RR}=$ 0.53 ; 95\% CI: $0.20-1.44 ; P=0.214)$ to $73 \%$ (RR $=0.27 ; 95 \%$ CI: $0.09-0.88 ; P=0.030$ ) (Supplementary Figure S4 online). Sensitivity analyses were not performed for the outcomes of number of attempts required or time to cannulation because of the small number of studies.

\section{Quality Assessment of Studies}

Seven of the studies were classified as high-quality studies (Jadad score $\geq 3$ ) and only one study was low quality (Jadad score $\leq 2$ ) (Supplementary Table S2 online). Subgroup analysis by Jadad score demonstrated that the significant heterogeneity was from the higher-quality studies for the outcomes of cannulation success $\left(P<0.001, I^{2}=85.790\right)$ and accidental arterial puncture $\left(P=0.003, I^{2}=69.590\right)$, indicating that heterogeneity was not due to the low quality of studies (Supplementary Figure S5 online).

\section{Publication Bias}

A funnel plot was used to qualitatively assess for publication bias, and Egger's and Begg's tests were done to calculate publication bias. There was no obvious evidence of asymmetry on the funnel plot and no evidence of publication bias for cannulation success rate by either the Egger's $(P=0.380)$ or Begg's test $(P=0.805)$ (Figure 5).

\section{DISCUSSION}

CVC insertion is a common procedure performed by physicians, and it is estimated that over 5 million CVCs are placed annually in the United States (4). Aberrant anatomy, history of prior CVC insertions, and thrombosis or scar tissue prevent successful cannulation and increase the risk of complications (4). CVC complication rates of $>15 \%$ have been reported, of which $20 \%$ are attributable to mechanical complications $(4,12)$. $2 \mathrm{D}$ real-time US-guided CVC insertion has shown substantial success in adult populations and current National Institute for Clinical Excellence guidelines recommend the use of US guidance for CVC insertion in both adults and children $(3,5,6)$.

The current meta-analysis demonstrates that $2 \mathrm{D}$ real-time US-guided CVC insertion in children was associated with significantly higher success rates and fewer attempts required for cannulation. There was also a reduction in the risk of accidental arterial puncture, which did not reach statistical significance, likely due to inadequate sample size.

US-guided CVC insertion in the pediatric population proved beneficial among both junior and senior operators, and the degree to which operator experience influences the success of catheterization seems obvious but remains controversial. Froehlich et al. (13) conducted an observational cohort study involving 212 pediatric patients ( 119 with US guidance and 93 with LM guidance), and reported a significant reduction in the number of attempts required for successful cannulation with 


\section{Systematic Review}

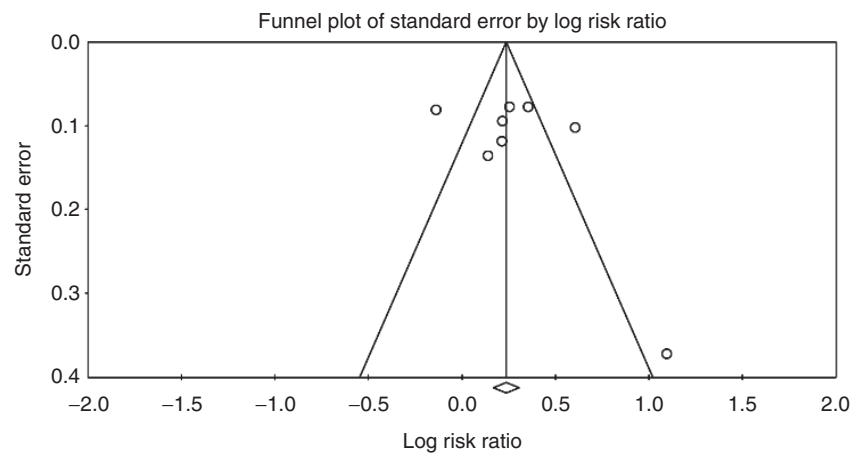

Figure 5. Funnel plot assessing publication bias (analyzing the effect of ultrasound-guided central venous catheter insertion on cannulation success rate among pediatric patients).

the use of US among residents and fellows, but not attending physicians. US-guided CVC insertion significantly reduced the time required for cannulation among the resident physicians ( 405 vs. 919 s, $P=0.02$ ), but not fellows ( 124 vs. 153 s, $P=0.067$ ) or attendings (100 vs. $340 \mathrm{~s}, P=0.32$ ), compared to LM-guided CVC insertion (13). The number of accidental arterial punctures was similar between both US- and LM-guided technique groups in all operator groups, except for a significant reduction among fellows $(P=0.03)(13)$. In the case of inexperienced operators, including resident physicians, US guidance helps visualize anatomy, therefore, significantly reducing the time required for cannulation and improving success (13). With more experienced operators already familiar with the landmark anatomy, US guidance confirms the location of vascular structures, defines aberrant anatomy, and increases the likelihood of successful cannulation $(13,14)$.

US guidance allows for visualization of the vasculature and identification of aberrant vessels, which may potentially prevent successful CVC insertion and result in complications. Denys and Uretsky (14) studied 200 patients and reported that the internal jugular vein was outside of the predicted landmark path in 5.5\% of the patients. Although US-guided CVC insertion is beneficial at all sites, including the internal jugular, subclavian, and femoral veins, the complications vary by site (7). The incidence of a posteriorly located carotid artery, which predisposes the patient to accidental carotid artery puncture if the needle transverses the internal jugular vein, has been reported to be as high as $54 \%$ (3). The incidence of arterial puncture with the subclavian approach has been reported as high as $12 \%$ (15). Casado-Flores et al. (16) conducted a cohort study involving 308 critically ill children (235 subclavian, 63 femoral, 10 jugular vein), and reported the highest incidence of arterial puncture occur with the femoral vein approach (6.3\%), followed by subclavian (5.1\%), and jugular vein (0.0\%). Subclavian vein catheterization was associated with the greatest risk of overall complications ( 60.9 vs. $53.7 \%$ for femoral and $33.3 \%$ for jugular, $P=0.02$ ) with a $2.5 \%$ risk of pneumothorax and $1.2 \%$ risk of hemothorax (16).

Patient age and weight have been shown to impact cannulation success. Froehlich et al. (13) reported that children in the low-weight group (median weight $<16.25 \mathrm{~kg}$ ) had lower success rates and required more placement attempts for both techniques, compared to children in the high-weight group (median weight $>16.25 \mathrm{~kg}$ ). Success rates were $83.0 \%$ for the LM-guided group and $79.3 \%$ for the US-guided group for children $<16.3 \mathrm{~kg}$, whereas success rates were as high as $95.0 \%$ for the LM group and $100.0 \%$ for the US group among children $>16.3 \mathrm{~kg}$ (13). The rate of accidental carotid artery puncture was also higher among children $<16.3 \mathrm{~kg}$ in both US (15.4 vs. $3.0 \%$ ) and LM groups (24.5 vs. $12.5 \%$ ), compared to children $>16.3 \mathrm{~kg}$ (13). The difficulty in achieving successful cannulation among neonates can be attributed in part to the small diameter of the vessels, making it difficult to locate even under US visualization (17). Mortensen et al. (17) reported correlations between body weight and surface area with vein diameter, with a stronger correlation for femoral veins compared to internal jugular veins. Hayashi et al. (18) conducted a cohort study assessing the use of US-guided CVC insertion in 106 children $<20 \mathrm{~kg}$ and reported significantly lower success rates in infants $<3 \mathrm{mo}(81.3$ vs. $100.0 \%, P<0.05)$ and infants $<4 \mathrm{~kg}(78.6$ vs. $100.0 \%, P<0.05)$ compared to children $>3$ mo and $>4 \mathrm{~kg}$.

Despite recommendations and documented benefits for US-guided CVC insertion, it has yet to gain widespread support and its use remains low in both adults and children (19). Bailey et al. (20) conducted an electronic survey among members of the Society of Cardiovascular Anesthesiologists, and reported that $37 \%$ of respondents never used US, whereas only $8 \%$ of respondents always used US for CVC catheterization. McGrattan et al. (21) conducted a survey involving 1,455 members of the Association of Anesthetists of Great Britain and Ireland, and reported that only $27 \%$ of respondents used US as their first choice for internal jugular cannulation, while $30 \%$ preferred palpation and 50\% preferred surface LMs. Similarly, in the pediatric population, Bosman et al. (19) conducted a survey among members of the Association of Pediatric Anesthetists in the United Kingdom and reported that $76 \%$ of respondents believed US guidance was beneficial, while $68 \%$ of respondents used US guidance, and only $39 \%$ used it routinely.

Although the results of this meta-analysis are significant, there are limitations to this study due to the variation and heterogeneity of the RCTs. The enrollment criteria used in each study differed in regards to age of the child, health and comorbidities of the patients, and the indication for CVC insertion. Given the difficulty of CVC insertion in younger children, more studies specifically involving neonates and preterm infants are required. The site of CVC insertion also differed between studies. Most studies involved the internal jugular vein, one study involved femoral vein, and one study included a combination of subclavian and internal jugular vein cannulation. Further studies investigating CVC insertion involving the femoral and subclavian vein are required. Although this study stratified between experienced and inexperienced operators, only one study involved junior residents and further studies involving resident physicians are required. The experience of the operator with anatomic LM and US-guided CVC placement differed between studies. The environment in which the 
CVC was placed also differed. Most of the studies were conducted prior to elective cardiovascular surgery and more studies involving emergent placements in the intensive care and emergency department are required.

In addition to the heterogeneity among the included studies, there are limitations to the quality of the included studies. Qualitative assessment of the studies demonstrated that seven of the eight RCTs were high-quality studies (Jadad score $\geq 3$ ), and subgroup analysis identified significant heterogeneity among the high-quality studies, indicating that the heterogeneity was due to other factors, rather than the lower-quality studies. However, most of the studies were not blinded, which might have generated a risk of observer bias. Furthermore, the Jadad scale mainly assesses the quality of reporting, rather than the actual methodological quality since specific details may not have been reported. To further evaluate the effect of each individual study on the overall effect sizes, sensitivity testing was conducted, and demonstrated that overall improvements in success rates and reductions in accidental arterial punctures were not significantly different by the removal of any specific study.

Despite these limitations, this study demonstrates that US guidance improves CVC insertion success rates, efficacy, and safety among pediatric patients. Given the number of CVC insertions performed and the risk of morbidity associated with LM-guided CVC insertions, US guidance should be utilized for CVC placements in most, if not all, pediatric patients.

\section{METHODS \\ Study Selection}

A comprehensive search for all published RCTs evaluating the use of real-time 2D US-guided CVC insertion in pediatric patients $<18 \mathrm{y}$ of age was conducted using PubMed, Cochrane Central Registry of Controlled Trials, and Google Scholar (1966-2015). Additional citations were searched, using the references of the articles retrieved from prior publications. The last search was conducted on October 14, 2015. Keywords used in the search included combinations of "ultrasound", "ultrasound guided", "central venous catheter", "catheter", "children", and "pediatric". Studies were included if they compared the use of real-time US-guided CVC insertion with anatomic LM-guided CVC placement in pediatric patients $<18$ y of age. In case of duplicate publications, only the most recent and updated report of the clinical trial was included.

\section{Data Extraction}

Articles retrieved from the searches were assessed for eligibility, and data pertaining to patients, intervention, control groups, outcomes, and methodology were abstracted (Figure 6). Two investigators independently extracted and assessed articles for eligibility. Discrepancies were resolved by discussion and consensus, and if necessary, with the assistance of other trained investigators in the department.

Primary clinical outcomes of interest included cannulation success rate and incidence of accidental arterial puncture. Secondary outcomes included number of attempts required and time to cannulation.

\section{Quality Assessment of Studies}

Quality assessment was independently performed by the two investigators using the Jadad scale, a widely utilized tool to assess methodological quality of clinical trials (22). Individual studies were assessed for randomization, blinding, and description of patient withdrawal and dropouts to generate a Jadad score between 0-5. Discrepancies were resolved by discussion and consensus between the two investigators and if necessary, with the assistance of other trained investigators in the department.

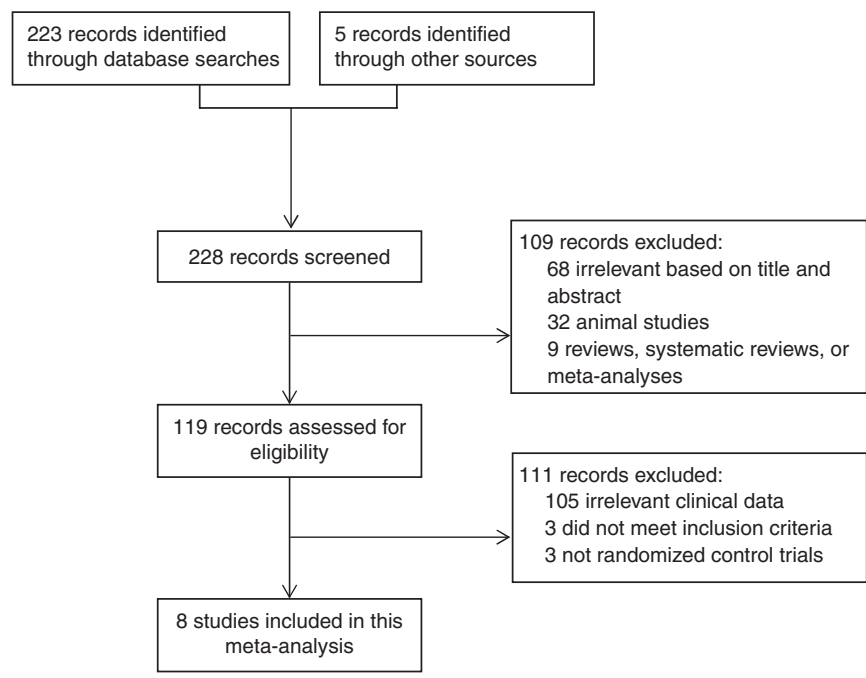

Figure 6. CONSORT diagram detailing the study selection process.

\section{Statistical Analysis}

For each trial, RR with a 95\% CI for success rate and incidence of accidental arterial puncture were calculated. MD and a $95 \%$ CI for continuous data including number of attempts required and time to cannulation were calculated. Meta-analysis of the pooled data was performed using the Comprehensive Meta-Analysis software Version 3 (Biostat, Englewood, NJ). For studies reporting zero events in any group, a continuity correction factor of 0.5 was adopted to calculate the RR and variance. In the event of zero events in both groups, the $\mathrm{RR}$ was not calculable and the study was excluded from the metaanalysis. Both the fixed-effects model and random-effects model were considered, depending on the heterogeneity of the included studies. To assess the heterogeneity between studies, both Cochrane's Q statistic and $I^{2}$ statistic was used. Heterogeneity was considered statistically significant when $P<0.05$ or $I^{2}>50$. If heterogeneity was observed, data were analyzed using a random-effects model. Conversely, in the absence of heterogeneity, a fixed-effects model was assumed. Sensitivity analyses were conducted to determine the influence of each study on the overall relative risk estimates by omitting each study in succession. Publication bias regarding the primary outcome (cannulation success rate) was first visually evaluated by a funnel plot, and further evaluated using Egger's and Begg's tests. A two-tailed $P$ value of $<0.05$ was considered statistically significant. Subgroup analysis was performed based on operator experience (junior operators were defined as resident physicians in training, while senior operators were defined as fellows who have completed residency training and are in fellowship training or attending physicians) and the site of cannulation (internal jugular, subclavian, and femoral vein).

\section{SUPPLEMENTARY MATERIAL}

Supplementary material is linked to the online version of the paper at http:// www.nature.com/pr

Disclosures: All authors listed declare that there are no conflicts of interest, and have not accepted financial sponsorship in producing and presenting this article.

\section{REFERENCES}

1. Randolph AG, Cook DJ, Gonzales CA, Pribble CG. Ultrasound guidance for placement of central venous catheters: a meta-analysis of the literature. Crit Care Med 1996;24:2053-8.

2. Palepu GB, Deven J, Subrahmanyam M, Mohan S. Impact of ultrasonography on central venous catheter insertion in intensive care. Indian J Radiol Imaging 2009;19:191-8.

3. Troianos CA, Hartman GS, Glas KE, et al.; Councils on Intraoperative Echocardiography and Vascular Ultrasound of the American Society of Echocardiography; Society of Cardiovascular Anesthesiologists. Special articles: guidelines for performing ultrasound guided vascular cannu- 
lation: recommendations of the American Society of Echocardiography and the Society Of Cardiovascular Anesthesiologists. Anesth Analg 2012;114:46-72.

4. McGee DC, Gould MK. Preventing complications of central venous catheterization. N Engl J Med 2003;348:1123-33.

5. National Institute for Clinical Excellence. Guidance on the use of ultrasound locating devices for placing central venous catheters. Technical Appraisal Guidance, 2002. https://www.nice.org.uk/ guidance/ta49.

6. Grebenik CR, Boyce A, Sinclair ME, Evans RD, Mason DG, Martin B. NICE guidelines for central venous catheterization in children. Is the evidence base sufficient? Br J Anaesth 2004;92:827-30.

7. Wu SY, Ling Q, Cao LH, Wang J, Xu MX, Zeng WA. Real-time twodimensional ultrasound guidance for central venous cannulation: a metaanalysis. Anesthesiology 2013;118:361-75.

8. Lee C, Chamberlain Ronald S. Ultrasound guided central venous catheter insertion: is safer, but in whose hands? A meta-analysis. 10th Annual Academic Surgical Congress 2015. (www.asc-abstracts.org).

9. Karimi-Sari H, Faraji M, Mohazzab Torabi S, Asjodi G. Success rate and complications of internal jugular vein catheterization with and without ultrasonography guide. Nurs Midwifery Stud 2014;3:e23204.

10. Aouad MT, Kanazi GE, Abdallah FW, et al. Femoral vein cannulation performed by residents: a comparison between ultrasound-guided and landmark technique in infants and children undergoing cardiac surgery. Anesth Analg 2010;111:724-8.

11. Bruzoni M, Slater BJ, Wall J, St Peter SD, Dutta S. A prospective randomized trial of ultrasound- vs landmark-guided central venous access in the pediatric population. J Am Coll Surg 2013;216:939-43.

12. Srisan P, Juhong S, Kanjanapatanakul W. Central venous catheterization related complications in Pediatric Intensive Care Unit at Queen Sirikit National Institute of Child Health. J Med Assoc Thai 2014;97 Suppl 6:S83-8.

13. Froehlich CD, Rigby MR, Rosenberg ES, et al. Ultrasound-guided central venous catheter placement decreases complications and decreases placement attempts compared with the landmark technique in patients in a pediatric intensive care unit. Crit Care Med 2009;37:1090-6.

14. Denys BG, Uretsky BF. Anatomical variations of internal jugular vein location: impact on central venous access. Crit Care Med 1991;19:1516-9.
15. Citak A, Karaböcüoğlu M, Uçsel R, Uzel N. Central venous catheters in pediatric patients-subclavian venous approach as the first choice. Pediatr Int 2002;44:83-6.

16. Casado-Flores J, Barja J, Martino R, Serrano A, Valdivielso A. Complications of central venous catheterization in critically ill children. Pediatr Crit Care Med 2001;2:57-62.

17. Mortensen JD, Talbot S, Burkart JA. Cross-sectional internal diameters of human cervical and femoral blood vessels: relationship to subject's sex, age, body size. Anat Rec 1990;226:115-24.

18. Hayashi $Y$, Uchida $O$, Takaki $O$, et al. Internal jugular vein catheterization in infants undergoing cardiovascular surgery: an analysis of the factors influencing successful catheterization. Anesth Analg 1992;74:688-93.

19. Bosman M, Kavanagh RJ. Two dimensional ultrasound guidance in central venous catheter placement; a postal survey of the practice and opinions of consultant pediatric anesthetists in the United Kingdom. Paediatr Anaesth 2006;16:530-7.

20. Bailey PL, Glance LG, Eaton MP, Parshall B, McIntosh S. A survey of the use of ultrasound during central venous catheterization. Anesth Analg 2007;104:491-7.

21. McGrattan T, Duffty J, Green JS, O'Donnell N. A survey of the use of ultrasound guidance in internal jugular venous cannulation. Anaesthesia 2008;63:1222-5.

22. Jadad AR, Moore RA, Carroll D, et al. Assessing the quality of reports of randomized clinical trials: is blinding necessary? Control Clin Trials 1996;17:1-12.

23. Verghese ST, McGill WA, Patel RI, Sell JE, Midgley FM, Ruttimann UE. Ultrasound-guided internal jugular venous cannulation in infants: a prospective comparison with the traditional palpation method. Anesthesiology 1999;91:71-77.

24. Verghese ST, McGill WA, Patel RI, Sell JE, Midgley FM, Ruttimann UE. Comparison of three techniques for internal jugular vein cannulation in infants. Paediatr Anaesth 2000;10:505-11.

25. Chuan WX, Wei W, Yu L. A randomized-controlled study of ultrasound prelocation vs anatomical landmark-guided cannulation of the internal jugular vein in infants and children. Paediatr Anaesth 2005;15:733-38.

26. Ovezov A, Zakirov I, Vishnyakova M. Effectiveness and safety of the internal jugular vein catheterization in pediatrics: ultrasound navigation vs anatomical landmarks (a prospective, randomized, double-blind study). Int Care Med 2010;36:S275. 